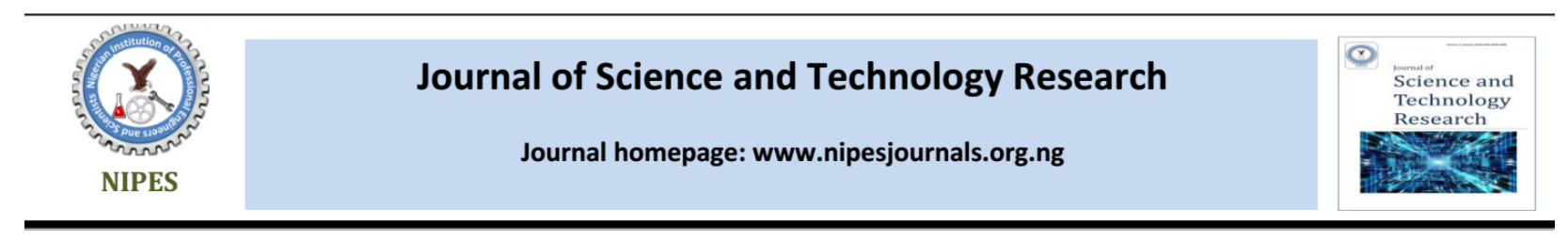

\title{
Duty Cycle Analysis of Radio Spectrum Profile Utilization for Cellular Bands
}

\author{
Isa, A. A.*, Akanni, J ${ }^{1}$., Thomas, C. T ${ }^{2}$., Alao, R. $A^{3}$, Adeshola, A. $S^{4}$ \\ ${ }^{*}, \mathbf{1 , 3 , 4}$ Department of Electrical and electronics Engineering, University of Ilorin, Ilorin, Kwara State Nigeria \\ ${ }^{2}$ Department of Electrical and Information Engineering, Achievers University, Owo, Ondo State, Nigeria
}

\begin{tabular}{|c|c|}
\hline Article Info & Abstract \\
\hline $\begin{array}{l}\text { Keywords: } \\
\text { Spectrum occupancy, Duty cycle, } \\
\text { Cognitive Radio (CR), } 3 G\end{array}$ & \multirow{3}{*}{$\begin{array}{l}\text { The high increase in the growth of wireless devices with the present } \\
\text { static radio spectrum management has created an inadequacy in the } \\
\text { available radio spectrum and presently the spectrum regulatory } \\
\text { bodies are of the view that static spectrum management approach } \\
\text { giving right of way to use licensed is still efficient. In this paper } \\
\text { spectrum occupancy of GSM } 900 \mathrm{MHz} \text {, GSM } 1800 \mathrm{MHz} \text { and } 3 \mathrm{G} \text { are } \\
\text { investigated. The measurement is done with Advantest U374l } \\
\text { spectrum analyzer with the frequency range of } 9 \mathrm{kHz} \text { to } 3 \mathrm{GHz} \text { using } \\
\text { energy detection method and selecting a } 10 \mathrm{dBm} \text { noise floor value as } \\
\text { proposed by the International Telecommunication Union (ITU). The } \\
\text { study reveals a duty cycle of } 35.31 \% \text {, 9.59\% and } 28.08 \text { for GSM } 900 \\
\text { MHz, } 1800 \mathrm{MHz} \text { and } 3 G \text { respectively. The results show that the } \\
\text { spectrum is highly underutilized. }\end{array}$} \\
\hline $\begin{array}{l}\text { Received } 19 \text { April } 2020 \\
\text { Revised } 26 \text { April } 2020 \\
\text { Accepted 07May } 2020 \\
\text { Available online 01 June } 2020\end{array}$ & \\
\hline $\begin{array}{l}\text { https://doi.org/10.37933/nipes/2.2.2020.16 } \\
\text { https://nipesjournals.org.ng } \\
\text { ISSN-2682-5821/@ 2020 NIPES Pub. } \\
\text { All rights reserved. }\end{array}$ & \\
\hline
\end{tabular}

\section{Introduction}

Wireless technology offers more flexible and inexpensive ways of communication and with four key comparative advantages over the wired technology - increased efficiency, high availability, greater flexibility and mobility for users at a far better reduced cost of installation and maintenance [1]. The high increase in the growth of wireless devices with the present static radio spectrum management has created an inadequacy in the available radio spectrum [2], and presently the spectrum regulatory bodies are of the view that static spectrum management approach giving exclusive right of way to use licensed is still efficient [3]. The global monthly data traffic grew by about 69\% from 1.5 exabyte in 2013 to 2.5 exabyte at the end of year 2014 and this is expected to reach up to 24.5 exabyte in 2019 and beyond that as forecasted by Cisco visual networking index [4]. This static allocation of radio spectrum is no longer adequate to grant access to the exponential growth of the wireless device because some portions of the radio spectrum are heavily used while the others are rarely used or not used at all; thus the inadequate sharing of the radio spectrum among users can lead to the opening of unwanted denial of service event [5]. In addition, the demand for wireless coverage, capacity, connectivity and services will continually expand and a critical barrier is the scarcity of the radio spectrum because it is fixed and cannot be expanded.

In view of this spectrum constraint, an obvious question is how efficient is the current use of the radio spectrum? Quantitatively, spectral efficiency is measure in bits per second per Hertz (bps/Hz) 


\section{A.A. Isa et al./ NIPES Journal of Science and Technology Research \\ 2(2) 2020 pp. $158-165$}

which is the amount of data transmitted per unit bandwidth, although this efficiency has steadily increased due to technical improvement $[6,7]$ but the growth rate has being declined [8], so due to this congestion, improving the state of spectral efficiency by other means is necessary for the growth of wireless networks. In addition, current spectrum management also has another serious operational problem as several licensed bands are not efficiently utilized with utilization varying abysmally over frequency, space and time and it was discovered through actual spectral occupancy measurements that vast portions of the licensed radio spectrum are randomly or rarely used by the licensed users [9-17].

One of the approach to solve the challenges of static spectrum management is the use of cognitive radio technology, which has undergone extensive research for almost two decades [18] and based on the principle of Dynamic Spectrum Access (DSA) technique [19]; performing key functions spectrum sensing, spectrum management and decision, spectrum sharing and spectrum mobility [19]. In the concept of Cognitive Radio (CR), licensed spectrum users are called Primary Users (PUs) and unlicensed Users are called Secondary Users (SUs). This SUs will access the spectrum when the interference on the PU receivers is low or below a prescribed level [20]. Figure 1 is showing the combination of a primary network and CR network. CR network can be divided into interwave, underlay and overlay networks [16], [21 - 25].

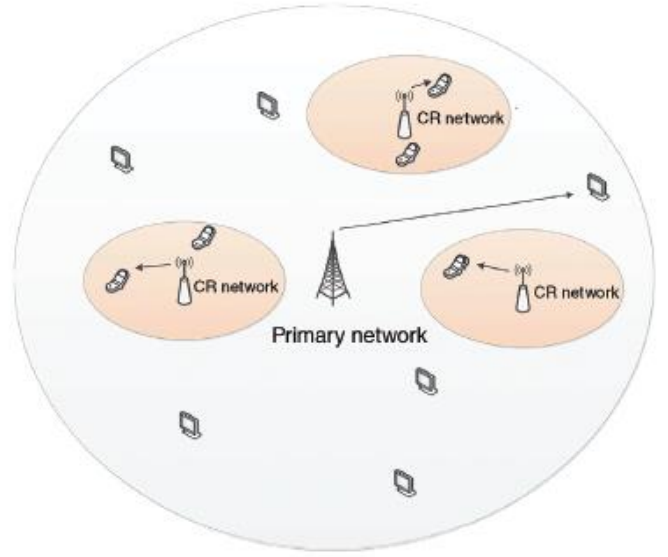

Figure 1: Cognitive Radio (CR) networks existing within a primary network

The rest of the paper is organized as follows: In Section II, relevant concept into the research is presented in few. The details on the field measurements conducted to evaluate the spectrum occupancy in the study area are presented in Section III. The results obtained in Section III were analyzed and discussed in Section IV. Section V, which is the last section, concludes the paper.

\section{Related Concept}

Several studies have been conducted to analyzed the licensed radio spectrum to evaluate the degree of spectrum usage allocation in many countries such as US, New Zealand, Germany, Singapore, China, Spain, Qatar, Vietnam, and India in order to evaluate and select suitable spectrum bands for the application of cognitive radio [26 - 37].

A research survey conducted by the Federal Communications Commission shows that the usage of allocated radio spectrum varied from $15 \%$ to $85 \%$ in the United State of America (USA) [38], stating that $22 \%$ allocated radio spectrum is utilized in urban area and as low as $3 \%$ in rural areas [38]. Islam et al. [30], performed a survey on radio spectrum occupancy measurement in Singapore, the goal was to analyzed the radio spectrum of the bands of diverse services and discover the less active 
bands that can be used for cognitive radio technology and some other future usage. The spectrum measurement result shows that the average utilization of the spectrum was $4.54 \%$ in Singapore.

In addition, in South Africa, the spectrum occupancy measurements conducted in the Hatfield area of Pretoria for ultra-high frequency (UHF) band, global system for mobile communications (GSM) $900 \mathrm{MHz}$ and GSM $1800 \mathrm{MHz}$ bands by [39] show variations in usage of the three spectrum bands. The UHF band shows an approximately occupancy of $20 \%$ and those of GSM $900 \mathrm{MHz}$ and GSM $1800 \mathrm{MHz}$ bands are at approximately $92 \%$ and $40 \%$ respectively [41]. Similar study carried out in Kampala, Uganda capital using GSM900, GSM1800, the universal mobile telecommunications system 2100 (UMTS2100) and long term evolution 2600 (LTE2600) radio spectrum bands showing variations in the frequency bands under consideration. The study reported average occupancy rates of $8.8 \%$ and $52.4 \%$ for both the uplink and downlink respectively in GSM900 band, $0.6 \%$ and $13.6 \%$ occupancy rates for GSM1800 band in the uplink and downlink respectively, $0.56 \%$ and $48.7 \%$ respectively for the UMTS2100 band and $0 \%$ and $0.6 \%$ respectively obtained for the LTE2600 band [40].

In [34] a spectrum survey was carried out in two different countries three locations, France with two locations and the other location Czech Republic with the set aim of correlating the measurements evaluation of the two countries in terms of their similarities and physical as relative to future radio spectrum management. The measurement campaign reveals that the spectrum utilization from $400 \mathrm{MHz}-3 \mathrm{GHz}$ in location 1,2 and 3 are $6.5 \%, 10.7 \%$ \& $7.7 \%$ respectively. Also, Jayavalan et al. [41], conducted measurements and analyses on the utilization of frequency spectrum in the cellular and TV bands in Malaysia. The purpose is to quantitatively explore the usage of the radio spectrum and look into the possibility of other wireless communication systems or cognitive radio to utilize and access the unused bands. The result analysis indicated that GSM 900 has an average duty cycle of $35 \%$, GSM $180010 \%$ and 3G, 26\%.

In [42] spectrum utilization on a simultaneous large scale measurement in south china to assess the realistic usage of the spectrum from $20 \mathrm{MHz}$ to $3 \mathrm{GHz}$ was performed The measurement shows the spectrum usage for each location has thus: for Guangzhou Trade Center and Guangzhou Canada Garden (urban areas) the average duty cycle are $41 \%$ and $29.8 \%$ respectively while Zhongshan in Suburban, and Jiangmen in rural are $35.9 \%$ and $21.6 \%$ respectively. More also, Chiang et al. [28] studied the profile usage of radio spectrum in New Zealand revealing that the average duty cycle of $6.21 \%$ and $5.72 \%$ utilization of spectrum, in the band, in an outdoor and indoor location respectively.

Similarly, in Nigeria, Adeseko et al. [43] conducted spectrum occupancy measurement and analysis in the 2.4 2.7 GHz Band in urban and rural environments; the measurement was conducted in Kwara State and the result obtained showed that the band is underutilized with an average duty cycle of $10.79 \%$ in urban area. In [44] an insight into spectrum occupancy was conducted at Gwarinpa District in Abuja. The report showed that the variation of usage of licensed spectrum in Abuja, the Nigeria Federal Capital Territory, ranges from $17 \%$ to $26 \%$ at $700-2400 \mathrm{MHz}$ frequency band. Also, in another study on spectrum occupancy measurements in Nigeria [45], which were carried out in Abuja and Katsina depicted variations in spectrum usage in the selected measurement locations with occupancies variations from $0.45 \%$ to $26 \%$.

\section{Methodology}

Measurements were conducted in the Department of Electrical and Electronics Engineering, University of Ilorin, Ilorin, Nigeria. The spectrum occupancy measurement set up as shown in Figure 2 is made up of Advantest U3741 spectrum analyzer with the frequency range of $9 \mathrm{kHz}$ to 3 


\section{A.A. Isa et al./ NIPES Journal of Science and Technology Research 2(2) 2020 pp. $158-165$}

$\mathrm{GHz}$, a personal computer (PC) connected to the spectrum analyzer with a general purpose interface bus (GPIB), LabView software installed on the PC to control the spectrum analyzer for data capturing purpose; the set up were kept indoor to prevent damage from rain. A coaxial cable is laid out through a window to connect the antenna and the spectrum analyzer.

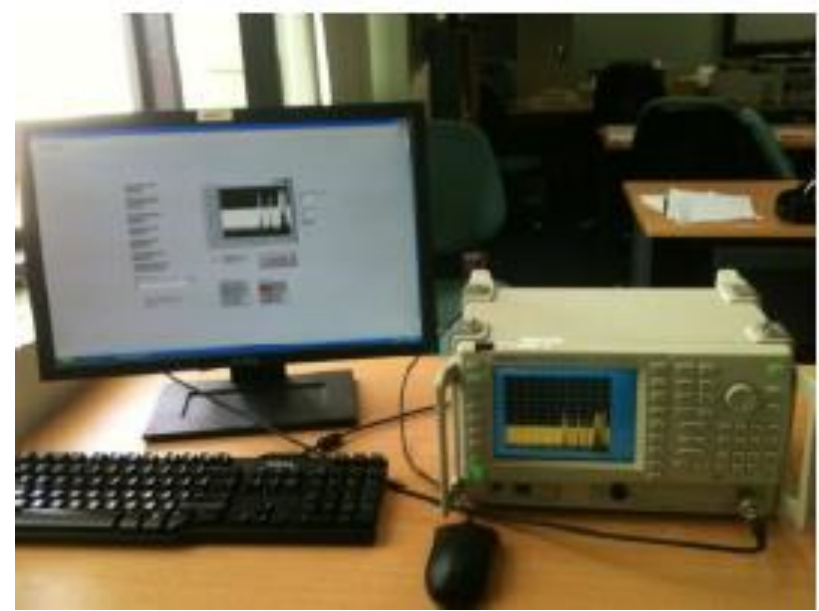

Figure 2: Measurement set up

Energy detection method is employed in this study. It compares the received signal energy in a certain frequency band to a predefined threshold. The decision threshold as recommendation in ITU spectrum monitoring handbook is $10 \mathrm{~dB}$ above the average noise floor [46]. However, the noise floor varies for different frequency range. The measurement was conducted for 24 hours and the received signal power collected by the spectrum analyzer in $\mathrm{dBm}$ is of the form

$$
Y_{i, j}=\left[\begin{array}{ccc}
P\left(t_{i} f_{j}\right) & \cdots & P\left(t_{i} f_{m}\right) \\
\vdots & \ddots & \vdots \\
P\left(t_{n} f_{j}\right) & \cdots & P\left(t_{n} f_{m}\right)
\end{array}\right]
$$

Where $t_{i}=t_{i}, t_{2}, \ldots t_{n}$ that denotes time slot and $f_{j}=f_{1}, f_{2}, \ldots f_{m}$ that also demotes the frequency being measured.

The duty cycle is the percentage ratio of the time a frequency band is occupied to the total time period at which the band is being occupied

$$
\text { Duty Cycle }=\frac{\text { Frequency band occupancy time }}{\text { Total time taken }} \times 100
$$

Table 1 shows the summary of the frequency range under consideration for the research work.

Table 1: Frequency Band

\begin{tabular}{lcc}
\hline Services Allocation & Frequency Range MHz & Bandwidth MHz \\
\hline GSM 900 & $880-960$ & 35 \\
GSM 1800 & $1710-1880$ & 75 \\
3G IMT-2000 & $1885-2200$ & 315 \\
& & \\
\hline
\end{tabular}




\section{Results and Discussion}

Figure 3 shows the measurement result for spectrum occupancy in GSM $900 \mathrm{MHz}$ band, the figure is divided into three section; the top most part is the Power Spectral Density (PSD) follows by the spectrum occupacy period and the last is the duty cycle. The average noise level was calculated was found to be $-92.8 \mathrm{dBm}$ and adding the decision threshold of $10 \mathrm{dBm}$ to give $-82.8 \mathrm{dBm}$ corresponding to a average duty cycle of $35.31 \%$. when compare with the study conducted by the author of [40] in Uganda with average duty cycle of 52.4\% shows that this band has the highest unlization level.
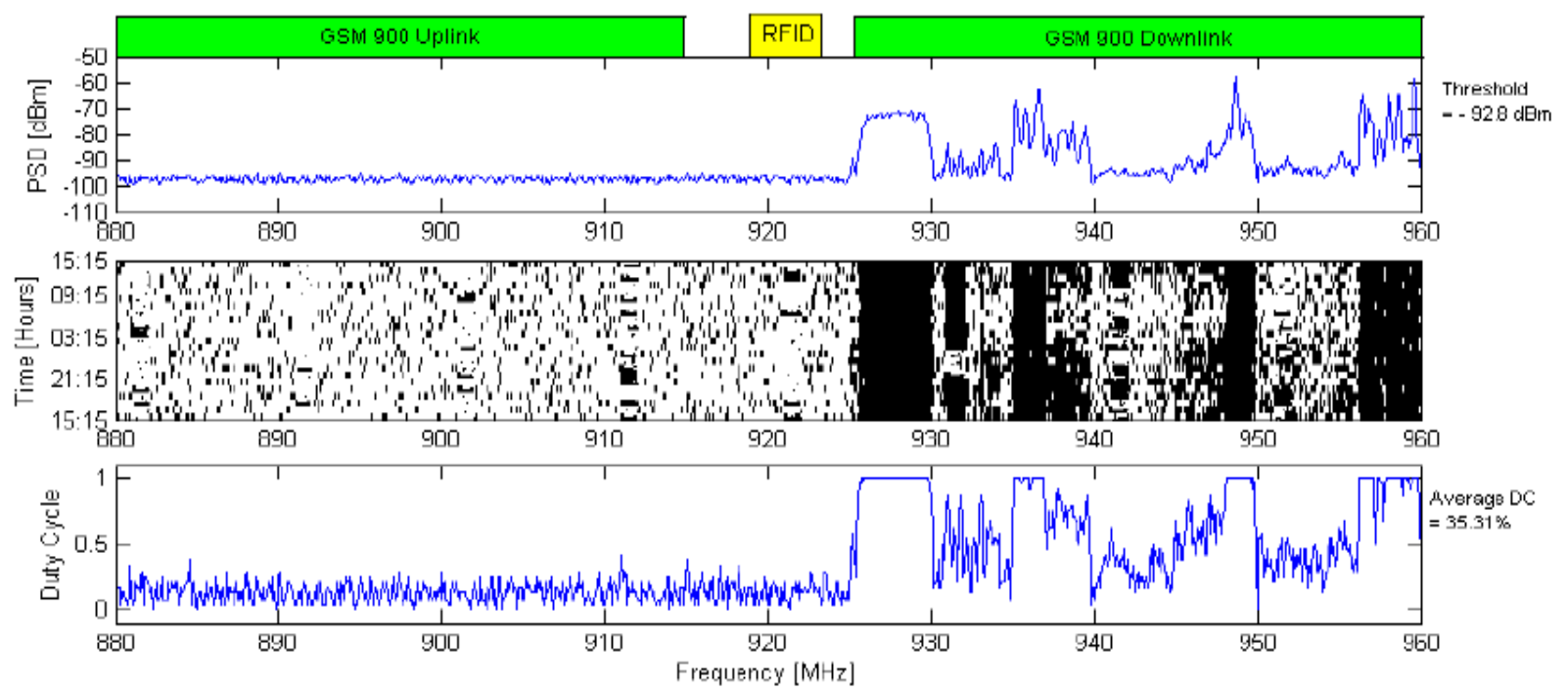

Figure 3: Spectrum Analysis for GSM 900 MHz Based on 24 Hours Measurement

Figure 4 shows the 3D plot measurement for GSM $900 \mathrm{MHz}$, it is observed that the occupancy between the uplink and downlink is not utilized in the same manner. The downlink seems to be fully occupied compared to uplink in the frequency of 880 to $915 \mathrm{MHz}$ which is sparsely or rarely occupied partly due to broadcasting of control channels by the base stations on the downlink with relatively high transmitting power.

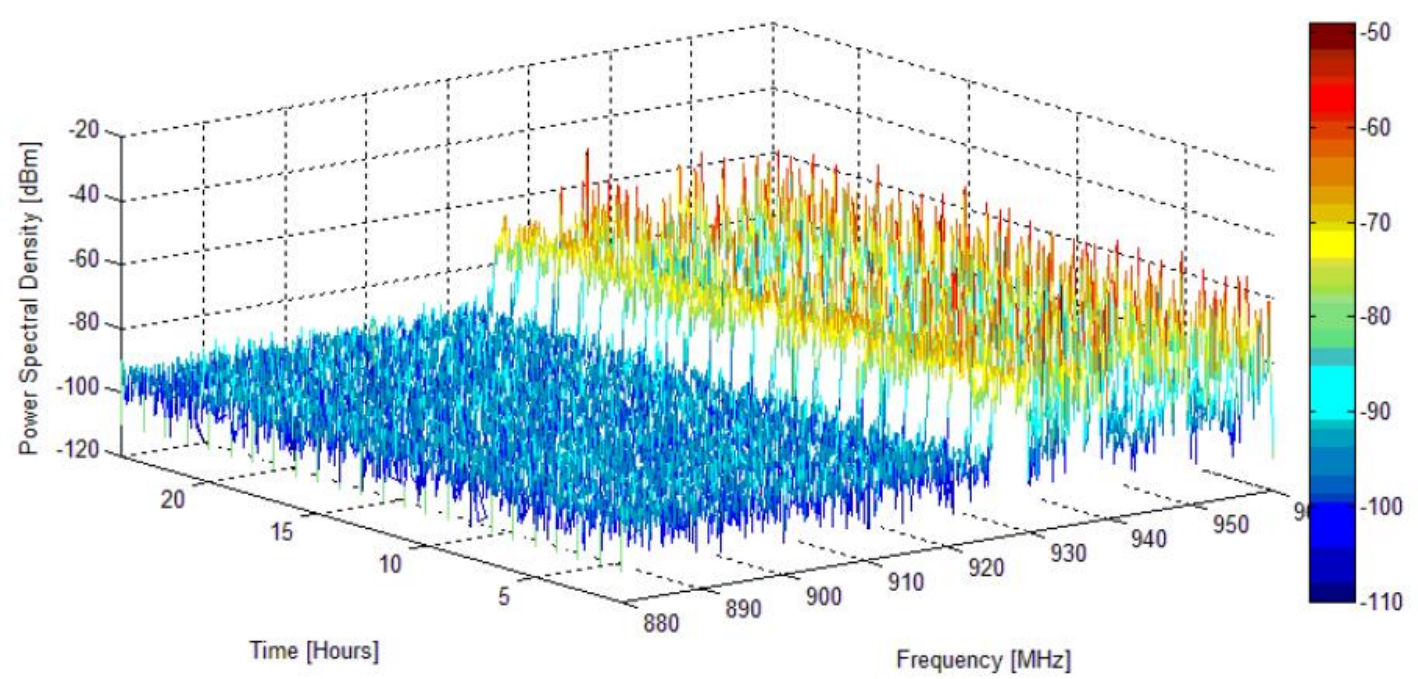

Figure 4: 3D plot of Spectrum Analysis for GSM $900 \mathrm{MHz}$ 
Figure 5 shows the spectrum of occupancy of GSM 1800 with average duty cycle of $9.59 \%$ and a threshold of $-90.7 \mathrm{dBm}$ in terms of power spectral density which is also in the region of research conducted in [3] producing value such as $-80.27 \mathrm{dBm},-84.63 \mathrm{dBm}$ and $-86.99 \mathrm{dBm}$ although there is a devaition because the research were conducted in cities (Ado-Ekiti, Akure and Ikeja). Figure 6 represent the spectrum occupancy of $3 \mathrm{G}$ band with a duty cycle of $28.08 \%$. The reason for very low utilization in the UMTS TDD and the FDD UL band is due to the measurement method employed. The energy detection method cannot efficiently detect the presence of wideband signals such as UMTS; to detect noise-like wideband signals, more advanced methods have to be employed (e.g. feature detection) [34] but the FDD (Frequency Division Duplex) uplink and downlink shows similiar characteristic to that of the GSM 900 downlink and uplink in which the downlink is occupied and the uplink is rarely occupied; although different modulation scheme is empoyed. Table 2 shows the summary of the average duty cycle of each frequency band at the measurement location.
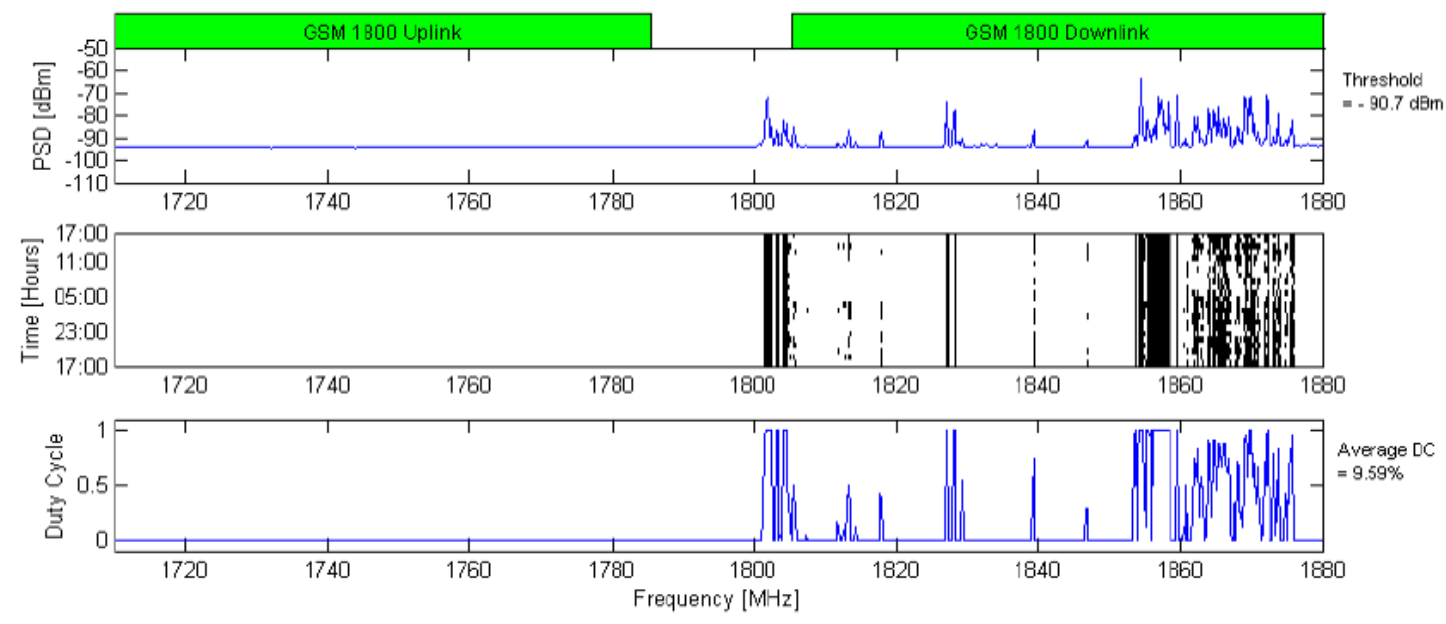

Figure 5: Spectrum Analysis for GSM 1800 MHz Based on 24 Hours Measurement
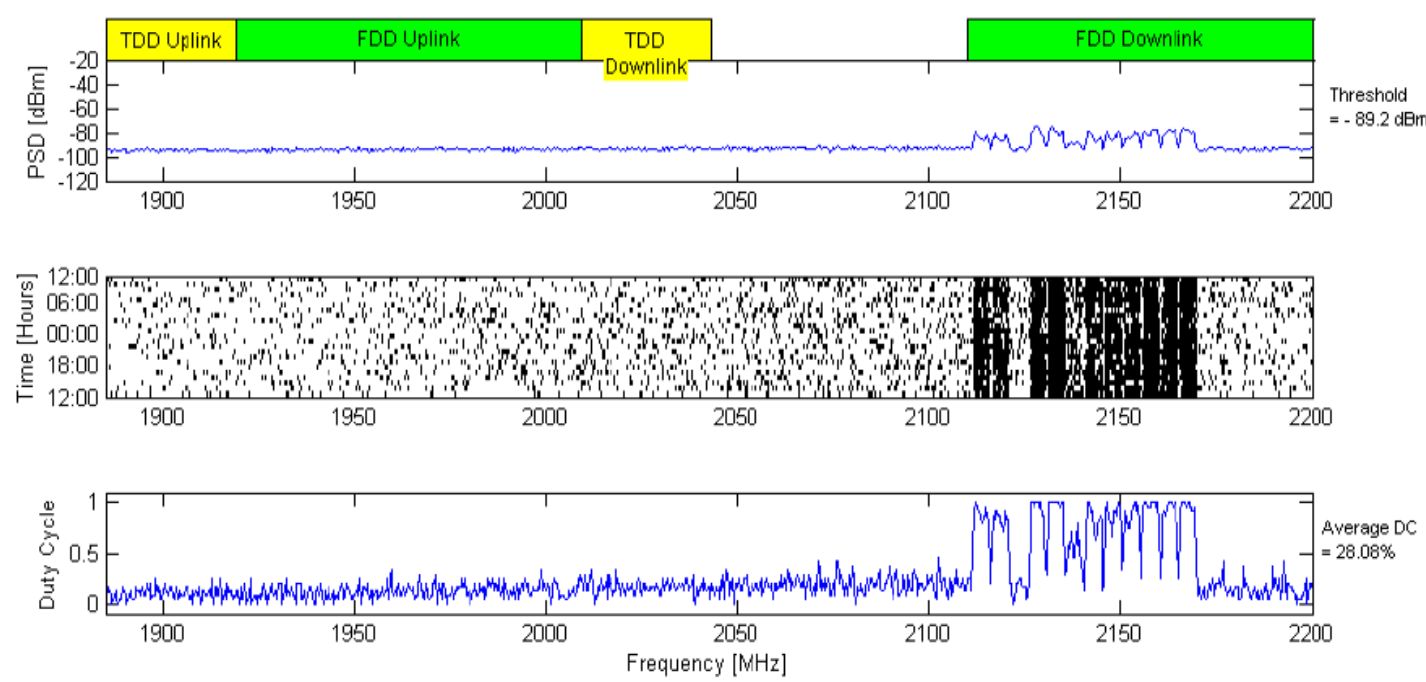

Figure 6: Spectrum Analysis for 3G GSM Band Based on 24 Hours Measurement 
A.A. Isa et al./ NIPES Journal of Science and Technology Research 2(2) 2020 pp. $158-165$

Table 2: Duty cycle of the selected bands

\begin{tabular}{lccc}
\hline Services Allocation & $\begin{array}{c}\text { Frequency Range } \\
\text { MHz }\end{array}$ & Bandwidth MHz & Duty cycle (\%) \\
\hline GSM 900 & $880-960$ & 35 & 35.31 \\
GSM 1800 & $1710-1880$ & 75 & 9.59 \\
3G IMT-2000 & $1885-2200$ & 315 & 28.08 \\
\hline
\end{tabular}

\section{Conclusion}

Duty cycle is showing the usage of the radio spectrum in each lisenced band of the radio spectrum, thus this research work investigate the available hole on the mobile radio spectrum for the incorporation of cognitive radio into the existing network to be able to effectively and efficiently use the allocated spectrum. Although it has already been established that static allocation of spectrum is not efficient and several studies has shown this; so this measurement is also done to further established this concept and therefore the need for the usage of cognitive radio technology.

\section{References}

[1] J. Akanni, A. A. Isa, R. A. Alao and C. T. Thomas (2020) "Assessment of Internet Service Provided Using UMTS Operators at the University of Ilorin Main Campus," Nigerian Journal of Technology, vol. 39, no. 2, pp. 500 - 505

[2] A. Ranjan and B. Singh (2016) "Design and Analysis of Spectrum Sesning in Cognitive Based on Energy Detection," In Proceding of the International Conference on Signal and Information Precessing, Vishnupuri, India, pp. 1 - 5.

[3] J. J. Popoola, O. A. Ogunlana, F. O. Ajie, O. Olakunle, O. A. Akiogbe, S. M. Ani-Initi, and S. K. Omotola (2016) "Dynamic Spectrum Access: A New Paradigm of Converting Radio Spectrum Wastage to Wealth," International Journal of Engineering Technologies, vol. 2, No.3, pp. $124-131$

[4] Cisco (2015) "Cisco Visual Networking Index: Global Mobile Data Traffic Forecast Update. (2014-2019)”. [Online]

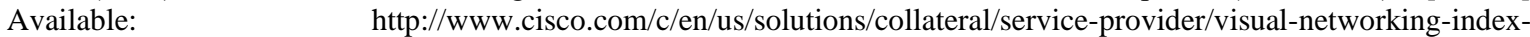
vni/white_paper_c11-520862.html

[5] Y. Arjoune and N. Kaabouch (2019) "A Comprehensive Survey on Spectrum Sensing in Cognitive Radio Networks: Recent Advances, New Challenges, and Future Research Directions," Sensor, vol. 19, no. 1, pp. 126

[6] T. Nechiporenko, P. Kalansuriya, C. Tellambura (2008). "Performance of Optimum Switching Adaptive M-QAM for Amplify-and-Forward Relays," IEEE Transactions on Vehicular Technology, vol. 58, no. 5, pp. 2258-2268

[7] G. Amarasuriya, M. Ardakani, C. Tellambura (2010). "Output-Threshold Multiple-Relay-Selection Scheme for Cooperative Wireless Networks," IEEE Transactions on Vehicular Technology, vol. 59, no. 6, pp. 3091 - 3097

[8] Qualcomn (2011) The visible light communications motivation. [Online] Available: http://visiblelightcomm.com/thevisible-light-communications-motivation/

[9] M. M. Buddhikot, K. Ryan, (2005) "Spectrum Management in Coordinated Dynamic Spectrum Access Based Cellular Networks", Proceeding of First IEEE International Conference on Dynamic Spectrum Access Networks, Baltimore, USA, November 8-11, pp. 299-307.

[10] G. Ding, Q. Wu, Y. Zou, J. Wang, Z. Gao, (2014) "Joint Spectrum Sensing and Transmit Power Adaptation in InterferenceAware Cognitive Radio Networks", Transaction on Emerging Telecommunications Technology, vol. 25, no. 2, pp. 231238

[11] J. Wang, G. Diang, Q. Shen, F. Song, (2014) "Spatial-Temporal Spectrum Hole Discovery: A Hybrid Spectrum Sensing and Geolocation Database Framework", Chinese Science Bulletin, vol. 59, no. 16, pp. 1896-1902.

[12] R. Shukla, D. Sharma, (2013) “Estimation of Spectrum Holes in Cognitive Radio using PSD”, International Journal of Information and Computer Technology, vol. 3, no. 7, pp. 663-670

[13] A.S. Kadhim, H.M. AI-Sabbagh, (2012) "Detecting the Spectrum Holes in The Primary Bandwidth of the Cognitive Radio Systems in Presence Noise and Attenuation”, International Journal of Communication Networks and System Science., vol. 5, no. 10 , pp. 685-690.

[14] S. Haykin, D.J. Ehomson, J.H. Reed, (2009) "Spectrum Sensing for Cognitive Radio", Proceeding of the IEEE, vol. 97, no. 5, pp. 849-977

[15] G. Zhao, J. Ma, G.Y. Li. T. Wu, Y. Kwon, A. Song, C. Yang, (2009) "Spatial Spectrum Holes for Cognitive Radio with Relay-Assisted Directional Transmission”, IEEE Transaction on Wireless Communication., vol. 8, no. 10, pp. 5270-5279.

[16] I.F. Akyildiz, W.Y. Lee, M. C. Vuran, S. Mohanty, (2006) "Next Generation/Dynamic Spectrum Access/Cognitive Radio Wireless Networks: A survey", Computer Networks, vol. 50, no. 13, pp. 2127-2159.

[17] S. Haykin, (2005) “Cognitive Radio: Brain-empowering Wireless Communications", IEEE Journal on Selected Areas in Communication., vol. 23, no. 2, pp. 201-220.

[18] P. Rawat, K. D. Singh \& J. M. Bonnin, (2016) "Cognitive Radio for M2M and Internet of Things: A Survey "Computer Communication", vol. 94, pp. $1-29$

[19] I.F. Akyildiz, W.Y. Lee, M.C. Vuran, S. Mohanty, (2008) "A Survey on Spectrum Management in Cognitive Radio Networks," IEEE Communication Magazine, vol. 46 no. 4, pp. 40 - 48.

[20] C. Tellambura, and S. Kusaladharma (2017) "An Overview of Cognitive Radio Networks" 


\section{A.A. Isa et al./ NIPES Journal of Science and Technology Research}

2(2) 2020 pp. $158-165$

[21] R. Menon, R. Buehrer and J. Reed (2005) "Outage Probability Based Comparison of Underlay and Overlay Spectrum Sharing Techniques," In Proceeding First IEEE International Symposium on New Frontiers in Dynamic Access Network, DYSPAN; pp 101- 109

[22] S. Srinivasa and S. A. Jafar (2007) "Cognitive Radios for Dynamic Spectrum Access - The Throughput Potential of Cognitive Radio: A Theoretical Perspective," In IEEE Communications Magazine, vol. 45, no. 5, pp. 73-79

[23] E. Hossain, D. Niyato and Z. Han (2009) "Dynamic Spectrum Access and Management in Cognitive Radio Networks," Cambridge University Press

[24] B. Wang and K. Liu (2011) “Advances in Cognitive Radio Networks: A survey," IEEE Journal of Selected Topics in Signal Processing, vol. 5, no. 1, pp. 5-23

[25] S. K. Sharma, T. E. Bogale, S. Chatzinotas, B. Ottersten, L. B. Le and X. Wang (2015) "Cognitive Radio Techniques under Practical Imperfection: A survey,” IEEE Communications Surveys and tutorials; vol. 17, no 4, pp. 1858 - 1884

[26] F. H. Sanders (1998) "Broadband Spectrum Surveys in Denver, CO, San Diego, CA, and Los Angeles, CA: Methodology, Analysis, and Comparative Results," In Proceeding of IEEE International Symposium on Electromagnetic Compatibility, vol. 2, pp. 988-993.

[27] M. A. McHenry, P. A. Tenhula, D. McCloskey, D. A. Roberson, and C. S. Hood (2006) "Chicago Spectrum Occupancy Measurements \& Analysis and a Long-term Studies Proposal," In Proceeding of Workshop on Technology and Policy for Accessing Spectrum (TAPAS), Boston, USA

[28] R. I. C. Chiang, G. B. Rowe, and K. W. Sowerby (2007) "A Quantitative Analysis of Spectral Occupancy Measurements for Cognitive Radio,” In Proceeding of IEEE Vehicular Technology Conference (VTC), Dublin, Ireland, pp. 3016- 3020.

[29] M. Wellens, J. Wu, and P. Mähönen (2007) "Evaluation of Spectrum Occupancy in Indoor and Outdoor Scenario in the Context of Cognitive Radio," In Proceeding of International Conference on Cognitive Radio Oriented Wireless Networks and Communications (CROWNCOM), Orlando, FL, USA, pp. 420-427.

[30] M. Islam, G. L. Tan, F. Chin, B. E. Toh, Y. C. Liang, C. Wang, Y. Y. Lai, X. Qing, S. W. Oh, C. L. Koh, and W. Toh (2008) "Spectrum Survey in Singapore: Occupancy Measurements and Analyses", In Proceeding of International Conference on Cognitive Radio Oriented Wireless Networks and Communications (CROWNCOM), Singapore, pp. 1-7.

[31] Y. Sixing, C. Dawei, Z. Qian, L. Mingyan, and L. Shufang (2012) "Mining Spectrum Usage Data: A Large-Scale Spectrum Measurement Study," IEEE Transactions on Mobile Computing, vol. 11, no. 6, pp. 1033-1046.

[32] M. Lopez-Benitez, A. Umbert, and F. Casadevall (2009) "Evaluation of Spectrum Occupancy in Spain for Cognitive Radio Applications," In Proceeding of Vehicular Technology Conference, VTC Spring

[33] K. A. Qaraqe, H. Celebi, A. Gorcin, A. El-Saigh, H. Arslan and M. S. Alouini (2009) "Empirical Results for Wideband Multidimensional Spectrum Usage," In Proceeding of IEEE 20th International Symposium on Personal, Indoor and Mobile Radio Communications, Tokyo, Japan, pp. 1262-1266.

[34] V. Valenta, R. Marsálek, G. Baudoin, M. Villegas, M. Suarez, and F. Robert (2010) "Survey on Spectrum Utilization in Europe: Measurements, Analyses and Observations," In Proceeding of the Fifth International Conference on Cognitive Radio Oriented Wireless Networks \& Communications (CROWNCOM), pp. 1-5.

[35] Q. B. Vo. Nguyen, Q. C. Le, Q. P. Le, D. T. Tran, T. Q. Nguyen, and M. T. Lam (2011) "Vietnam Spectrum Occupancy Measurements and Analysis for Cognitive Radio Applications," In Proceeding of International Conference on Advanced Technologies for Communications (ATC), pp. 135-143.

[36] K. Patil, K. Skouby, A. Chandra, and R. Prasad, (2011) "Spectrum Occupancy Statistics in the Context of Cognitive Radio," In Proceeding of $14^{\text {th }}$ International Symposium on Wireless Personal Multimedia Communications (WPMC), pp. 1-5.

[37] R. de Francisco (2010) "Spectrum Occupancy in the 2.36-2.4 GHZ band: Measurements and Analysis," In Proceeding of European Wireless Conference (EW), pp. 231-237

[38] J.J. Popoola, R. Van Olst, (2011) “Application of Neural Network for Sensing Primary Radio Signals in a Cognitive Radio Environment", In Proceeding of IEEE AFRICON, Livingstone, Zambia, September 13 - 15, pp. 1-6

[39] S. D. Barnes, P. A. J. van Vuuren, B.T. Maharaj (2013) "Spectrum Occupancy Investigation: Measurements in South Africa", Measurement, vol. 46, no. 9, pp. 3098-3112.

[40] G. Ayugi, A. Kisolo, T.W. Ireeta, (2015) "Telecommunication Frequency Band Spectrum Occupancy in Kampala Uganda", International Journal Research in Engineering and Technology, vol. 4, no. 9, pp. 390-396.

[41] S. Jayavalan, H. Mohamad, N. Moh'd Aripin, A. Ismail, N. Ramli, A. Yaacob, and M. A. Ng (2014) "Measurements and Analysis of Spectrum Occupancy in the Cellular and TV bands," Lecture Notes on Software Engineering, vol. 2, no. 2 pp. $133-138$

[42] Y. Liang, Y. Si-xing, W. Shuai, Z. Er-qing, H. Wei-jun, L. Shu-fang. (2012) "Quantitative Spectrum Occupancy Evaluation in China: Based on a Large Scale Concurrent Spectrum Measurement", School of Information and Communication Engineering, Beijing University of Posts and Telecommunications, China, The Journal of China Universities of Posts and Telecommunications, vol. 19 issue 3, pp. 122-128

[43] A. A. Ayeni, N. Faruk, O. W. Bello, O. A. Sowande, S. O. Onidare, and M. Y. Muhammad (2016) "Spectrum Occupancy Measurements and Analysis in the 2.4-2.7 GHz Band in Urban and Rural Environments" International Journal of Future Computer and Communication, vol. 5, no. 3, pp. 142 - 147

[44] B.G. Najashi, W. Feng, C. Kadri, (2013) "An Insight into Spectrum Occupancy in Nigeria", International Journal of Computer Science Issues, vol. 10, no. 1, pp. 394-399

[45] B.G. Najashi, M.D. Almustapha, A.S. Abdi, S.A. Ashurah, (2015) "Spectrum Occupancy Measurements in Nigeria: Results and Analysis," International Journal of Computer Science Issues, vol. 12, no. 4, pp. 156-165

[46] Radio communication Bureau, International Telecommunication Union (ITU), (2011) Handbook Spectrum Monitoring 